\title{
Modern models of endoprostheses and periprosthetic infection.
}

\author{
Shalginbay A. Baimagambetov ${ }^{1 *}$, Amanzhol S. Balgazarov ${ }^{1}$, Zhanatay K. Ramazanov ${ }^{1}$, Alexander A. \\ Markov $^{2}$, Andrey A. Ponomarev ${ }^{3}$, Raushan Kh. Turgumbayeva ${ }^{4}$, Malik N. Abdikarimov ${ }^{5}$
}

${ }^{1}$ Department of Traumatology, Research Institute of Traumatology and Orthopedics, Astana, Republic of Kazakhstan

${ }^{2}$ Department of Traumatology and Orthopedics with Course of Children's Traumatology, Tyumen State Medical University, Tyumen, Russian Federation

${ }^{3}$ Department of Geology of Oil and Gas Fields, Tyumen Industrial University, Tyumen, Russian Federation

${ }^{4}$ Department of Chemistry, Kazakh National Pedagogical University named after Abai, Almaty, Republic of Kazakhstan

${ }^{5}$ Department of Applied Chemistry, Kazakh National Research Technical University named after K.I. Satpaev, Almaty, Republic of Kazakhstan

\begin{abstract}
The main goal of the paper is to study epidemiology of infection complications after hip arthroplasty with modern models of endoprosthesis, using the research of other scientists. The authors used theoretic methods, which included analysis and review of literary sources. The authors found that modern foreign endoprostheses have significant advantages in terms of quality, functioning, and design. It is found that endoprosthesis component instability was most widespread causes of inflammatory process developments, as well as postsurgical hematoma, inflammation, postoperative wound edges necrosis, and others.
\end{abstract}

Keywords: Hip joint, Total hip replacement, Periprosthetic hip infection.

Accepted on April 16, 2018

\section{Introduction}

Today treatment and rehabilitation of patients with severe acquired and congenital pathology of hip joints are one of relevant issues in orthopaedics [1]. Endoprosthesis replacement is considered most effective among many known methods: it allows reaching high rehabilitation effect and significantly increasing the patients' life quality in a relatively short time [2]. The operation of total endoprosthesis replacement by complexity, extent of blood loss, threat of general and local complications takes the first place in orthopaedic surgery, and is fraught with numerous mistakes if made poorly [3].

According to foreign authors, the rate of prosthetic joint infection after first endoprosthesis replacement makes up $0.3-3.0 \%$ [4,5]. Forecasts for check-up operations are much worse, after them infection complications develop in $2.6-4.8 \%$ cases, and following a check-up operation in relation to infection process, backsets develop in $23.2-35.9 \%$ cases $[6,7]$. The infection rate varies depending on follow-up period of patient and makes up, according to different authors, from $0.3 \%$ to $2.22 \%$ in primary and to $5.9 \%$ in check-up operations [8-14].

\section{Materials and Methods}

In the course of research the authors used Medline $\AA$, Embase $\AA$ databases, which contain the information about infectious complications after hip arthroplasty. The search for publications in Russian in peer-reviewed journals using RSCI (Russian Science Citation Index electronic base) and Elibrary.ru scientific electronic library. The authors reviewed publications related to hip arthroplasty with the use of foreign endoprostheses in research centers and hospitals of the former USSR and having complications. Data analysis was carried out only by officially published papers in the press publications.

\section{Results}

Leading research centers of the USSR have adopted hip prostheses of the world manufacturers of Europe and USA early in the 90's. These were largely endoprostheses Zimmer (19.1\%), Muller (14.3\%), Waldemar Link (10.8\%), DePuy (14.2\%), Sulzer (7\%), Kirchner-in 5\%, Spotorno-in 4.6\%, Poldi- in $3.7 \%$, Zweymüller (3.1\%), Matisa $(2.6 \%)$. The next endoprostheses were used rarer: Wagner $(0.4 \%)$, Ortos $(0.2 \%)$, Lima-LTD (0.1\%) [15-19]. Literature review showed that during the adopting endoprosthesis replacement infectious complications were observed from $0.3 \%$ to $4.8 \%$ [20]. 
However, for the last 10-15 years the situation has changed for the better, since the ratio of foreign endoprostheses made $95 \%$ $[21,22]$.

According to Volokitina et al. [23], who maintained over 600 operations with European prostheses, infectious complication was in $0.9 \%$ patients. The experience in the application of modern foreign prostheses indicates significant advantages by design, quality, and exploitation [24]. Currently, new endoprostheses ESI, Fenix, BMSI appeared, which can be compared to foreign ones. These companies often use import raw materials to manufacture implants, they independently certified their production according to international standards, streamlined rigid internal control of production process. Infectious complication was observed from 1.2 to $1.8 \%$ $[25,26]$.

The following most probable causes of inflammatory process development were found: endoprosthesis components' instability; postsurgical hematoma; inflammation caused by reaction to suture material (suture sinuses); focal point of latent self-infection; postoperative wound edges necrosis, patient's non-compliance with rehabilitation programme in postoperative period; injuries in postoperative period; endoprosthesis components' destruction [27].

\section{Discussion}

Information presented in scientific papers regarding the usage of endoprostheses of world manufacturers such as Zimmera, Muller, Waldemar Link, Depuy, Sulzer, Kirschner, Spotorno, Poldi, Zweymüller in the territory of the former USSR indicates positive dynamics of results of treatment after arthroplasty, a decrease in infectious complications in early and late postoperative period. Thus, according to authors [28], doctors started to use endoprosthesis of the countries outside the CIS since 1994. Biomet endoprosthesis was used in 182 patients, Protek-in 19, Ortos-in 3, Lima-in 3. Out of 224 operations complications were observed in 5.9\% (13 patients). Suppuration in $3.1 \%$ (7), in 2 cases suppurative process was cut short, endoprostheses in others were removed. Dislocation in $2.7 \%$ (6 patients).

Davydov et al. [29] maintained hip replacement with "Endoprotetik Plus"-41 patients. Complications: fistula in 2 cases and in 1.5 months it was cut down, dehiscence-in 2, secondary regeneration, thrombophlebitis of hip vein-in 3 .

Statsenko et al. [30], 221 operations were maintained in 202 patients. Age from 19 to 90 years old. Average age-54 years. All Muller endoprostheses. Complications: suppurative-septic complications $-5.2 \%$.

For the period from 1996 to 2001 Shavpovalov et al. [31] switched to foreign EP "Zimmer" and "Waldemar Link". Complications; instability in $1.1 \%$, dislocation-in $2.2 \%$, suppuration (early-0.7\%, late-1.1\%).

All over the world the rate of infectious complication development is about $1 \%$ after primary endoprosthesis replacement, and in the case of check-up intervention the risk increases 4 times [32]. The main factors [33] contributing to suppuration are operation length over 3 hours $(90 \%)$, additional use of biological and synthetic materials $(77.8 \%)$, technical challenges $(71.4 \%)$, concurrent conditions $(76.9 \%)$, blood loss over $1 \mathrm{~L}(69.2 \%)$.

\section{Conclusions}

According to national registers of Spain, Canada, Norway, Australia, Great Britain, USA, Denmark, Finland, Sweden [34-40], the rate of check-up complications after endoprosthesis replacement makes up 2-14\%, while infection takes 2-3 rank place (0.6-16\%) in the structure of all causes of check-up interventions [41-43]. The analysis shows that infection often develops in men when there are interventions related to inflammatory diseases, hip fractures, and necrosis of head of femur.

Thus, after using foreign endoprostheses there is a decrease in the risk of periprosthetic infection, since prostheses are better by design, quality, and the high level of training operational staff by study centers of Europe and USA allowed getting positive results; while noting high survival rate of foreign prostheses $(97 \%)$ at the observation period $7-10$ years, there is a marked decline in infectious complication (0.3-4.8\%). Infectious complications, as a rule, were related to noncompliance with aseptics and antiseptics, operation length, problems of postoperative care, patient's social status (citizen or countryman).

\section{References}

1. Pearson OM, Lieberman DE. The aging of Wolff's "law" ontogeny and responses to mechanical loading in cortical bone. Am J Phys Anthropol 2004; 39: 63-99.

2. Prokopetz JZ, Losina E, Bliss R.L, Wright J, Baron JA, Katz JN. Risk factors for revision of primary total hip arthroplasty: a systematic review. BMC Musculoskelet Disord 2012; 13: 251.

3. Woolson ST, Watt JM. Use of autologous blood in total hip replacement. A comprehensive program. J. Bone Joint Surg 1991; 73: 76-80.

4. Bozic KJ, Kurtz SM, Lau E, Ong K, Vail TP, Berry DJ. The epidemiology of revision total hip arthroplasty in the United States. J Bone Joint Surg Am 2009; 91: 128-133.

5. Kurtz SM, Ong KL, Lau E. Prosthetic joint infection risk after TKA in the Medicare population. Clin Orthop Relat Res 2010; 468: 52-56.

6. Kaminskiy AV, Marchenkova LO, Pozdnyakov AV. Revision Hip Arthroplasty: Epidemiology, Causes, Risk Factors (foreign literature review). Herald of traumatology and orthopedics named after N.N. Priorov 2015; 2: 83-89.

7. Barrett L, Atkins B. The clinical presentation of prosthetic joint infection. J Antimicrob Chemother 2014; 69: 25-27.

8. Bauer TW, Parvizi J, Kobayashi N, Krebs V. Diagnosis of periprostetic infection. J Bone Joint Surg Am 2006; 88: 869-882. 
9. Lie SA, Engesaeter LB, Havelin LI, Gjessing HK, Vollset SE. Dependency issues in survival analyses of 55,782 primary hip replacements from 47,355 patients. Stat Med 2004; 23: 3227-3240.

10. Katz JN, Losina E, Barrett J. Association between hospital and surgeon procedure volume and outcomes of total hip replacement in the United States Medicare population. J Bone Joint Surg Am 2001; 83: 1622-1629.

11. Pulido L, Ghanem E, Joshi A. Periprosthetic joint infection: the incidence, timing, and predisposing factors. Clin Orthop 2008; 466: 1710-1715.

12. Phillips JE, Crane TP, Noy M. The incidence of deep prosthetic infections in a specialist orthopaedic hospital: a 15-year prospective survey. J Bone Joint Surg Br 2006; 88: 943-948.

13. Iamthanaporn K, Chareancholvanich $\mathrm{K}$, Pornrattanamaneewong C. Revision primary total hip replacement: causes and risk factors. Chotmaihet Thangphaet 2015; 98: 93-99.

14. Lindgren V, Gordon M, Wretenberg P. Deep Infection after Total Hip Replacement: A Method for National Incidence Surveillance. Infect Control Hospital Epidemiol 2014; 35: 1491-1496.

15. Shaposhnikov YG, Nuzhdin VI, Popov TP, Horani JG, Gorokhov VJ, Tereshkova EA. Total hip replacement. Materials of U1 Congress of CIS traumatologists, 1993.

16. Zaytsev VN, Kolomiets AA, Vayntrub S, Yakubov JN, Doronin VA. Comparative analysis of total hip arthroplasty. Scientific Conference on "Modern technologies in traumatology and orthopedy", Moscow, 1999.

17. Nuzhdin VI, Popov TP, Raenkulov T. Total hip replacement using modern design. Errors, dangers, complications and their prevention. Scientific Conference on "Modern technologies in traumatology and orthopedics", Moscow, 1999.

18. Tsodyks VM, Mitroshin AN. New principle of fixing the acetabular and femoral components in total hip arthroplasty. Materials of U1 Congress of CIS Traumatologists. Yaroslavl, 1993.

19. Zhadenov I, Gnetnev AM, Pozdnyakova BY. Ability to predict later septic complications after hip endoprosthesis. Traumatol Orthopedics Russ 2002; 1: 72-75.

20. Davydov SO, Sizonenko VA, Shilnikov VA, Zolotarev AV, Shatskaya MG, Koshkin OA. Experience of total hip endoprostheses surgery with domestic and foreign prosthesises. Materials of U11 Congress of Orthopaedic Trauma, Novosibirsk, 2002.

21. Delank KS. Increased polyethylene wear after cementless ABG I total hip arthroplasty. Arch Orthop Trauma Surg 2006; 126: 509-516.

22. Tihilov RM, Shapovalov VM. Hip arthroplasty guide. Saint Petersburg: ELBI-SPb, 2008.

23. Volokitina EA, Zaitseva OP, Kolotygin DA, Vishniakov AA. Local intraoperative and early postoperative complications after endoprosthetics of the hip. Orthopedics Genius 2009; 3: 72.

24. Akhtyamov IF, Kuzmin I. Pathogenetic features of infectious complications after total joint replacement. Scientific Conference on "New Technologies in Medicine", Barrow, 2000.

25. Pronskih AA, Aghajanian VV. Errors and complications in hip replacement. "Modern technologies in traumatology, orthopedics: errors and complicationsprevention, treatment”. Moscow: Int. Congress, 2004.

26. Zorya VI, Chemyanov IG, Shapoval AI. Poor outcomes and complications of total hip arthroplasty with implants of domestic production. Endoprosthesis surgery of major joints: Russian conference with international participation, devoted to 50th anniversary of the domestic production and 85th anniversary of Professor K.M. Sivash. Moscow, 2009.

27. Norkin IA, Shpinyak SP, Girkalo MV, Barabash AP. Surgical treatment outcomes of infectious complications of total large joints arthroplasty. Traumatol Orthoped Bull NN 2014; 3: 67-71.

28. Imamaliyev AS, Zorya V. 25 years of total hip arthroplasty. Scientific Conference on "Modern technologies in traumatology and orthopedics", Moscow, 1999 .

29. Davydov SO, Sizonenko VA, Shilnikov VA, Zolotarev AV, Shatskaya MG, Koshkin OA. Experience of total hip endoprostheses surgery with domestic and foreign prosthesises. Novosibirsk: Materials of U11 Congress of Orthopaedic Trauma, 2002.

30. Statsenko OA, Kalashnikov VV, Noskov VP. Complications associated with total hip arthroplasty. "Modern technologies in traumatology, orthopedics: errors and complications - prevention, treatment". Novosibirsk: Int. Congress, 2004.

31. Shapovalov VM, Tikhilov RM, Pechkurov AL, Trachuk AP. The concept of primary and revision hip arthroplasty. U11 Congress of Orthopaedic Trauma in Russia. Novosibirsk, 2002.

32. Perka C, Haas N. Der Chirurg; Zeitschrift fur alle Gebiete der operative [Periprosthetic infection]. Medizen 2011; 82: 218-226.

33. Arthursson AJ, Fumes O, Espehaug B, Havelin LI, Soreide JA. Prosthesis survival after total hip arthroplasty - does surgical approach matter? Analysis of 19304 Charnley and 6002 Exeter primary total hip arthroplasties reported Norwegian Arthroplasty Register. Acta Orthop 2007; 78: 719-729.

34. Tian W, DeJoing G, Brown M, Hsieh C, Zamfirov ZP, Horn SD. Looking upsteam: Factors shaping the demand for postacute joint replacement rehabilitation. Arch Phys Med Rehabil 2009; 90: 1260-1268.

35. http//nriweb.ihelse.net/eng/Annual_Report_2009.pdf

36. $\mathrm{http} / /$ earisview .com/2011/08/07/australian-national-jointregistry-2010-summary-on-hip-rep la cements/ 
37. Sibanda N, Copley LP, Lewsey JD, Borroff M, Gregg P, MacGregor AJ, Pickford M, Porter M, Tucker K, Van der Meulen JH. On behalf of the Steering Committee of the National Joint Registry (NJR) for England and Wales. Revision rates after primary hip and knee replacement in England between 2003 and 2006. PLoS Med 2008; 5: e 179.

38. Peltola M, Malmivaara A, Paavola M. Hip prosthesis introduction and early revision risk. A nationwide population-based study covering 39,125 operations. Acta Orthop 2013; 84: 25-31.

39. Ong KL, Lau E, Suggs J, Kurtz SM, Manley MT. Risk of subsequent revision after primary and revision total joint arthroplasty. Clin Orthop Relat Res 2010; 468: 3070-3076.

40. Dale H, Hallan G, Espehaug B, Havelin LI, Engesater LB. Increasing risjc df revision due to deep infection after hip arthroplasty' A'study on 97,344 primary total hip replacements in [the Norwegian Arthroplasty Register from 1987 to- 2007. Acta Orthop 2009; 80: 639-645.

41. Lindgren V, Garellick G, Karrholm J, Wretenberg P. The type of surgical approach influences the risk of revision in total hip arthroplasty. A study from the Swedish Hip Arthroplasty Register of 90,662 total hip replacements with 3 different cemented prostheses. Acta Orthop 2012; 83: 559-565.

42. Lachiewicz PF, Soileau ES. Changing indications for revision total hip arthroplasty. J Surg Orthop Adv 2005; 14: 82-84.

43. Hassan T, Birtwistle S, Power RA, Harper WM. Revision hip arthroplasty activity in a single UK health region: an audit of 1265 cases. Ann R Coll Surg Engl 2000; 82: 283-286.

\section{*Correspondence to}

Shalginbay A. Baimagambetov

Department of Traumatology

Research Institute of Traumatology and Orthopedics

Republic of Kazakhstan 